\title{
Subcutaneous Adiposity and Nutritional Status Among Children of Eastern-India
}

\author{
Debnath $\mathrm{S}^{1}$, Mondal $\mathrm{N}^{2}$, Sen $\mathrm{J}^{3}$
}

\section{Abstract}

Introduction: Skinfold thickness is now considered to be an important indicator of body composition and nutritional status. Assessment of subcutaneous adiposity is becoming very important due to increasing trend of overweight and obesity. The objectives of the present study were to determine age-sex specific subcutaneous adiposity using skinfold thicknesses and its use in assessment of nutritional status among children of Eastern-India. Material and Methods: The investigation was carried out among 1262 children (619 boys; 643 girls) aged 5-12 years of Darjeeling district, West Bengal. Anthropometric measurements of skinfold thickness were recorded using standard procedures. Age-sex specific smooth percentile curves of skinfold thickness were derived using the L, M and S model. Results: Sexual dimorphism was observed in TSF, SSF, SISF, PBF, $\Sigma 2$ SKF and $\sum 4$ SKF measurements between sexes in children $(p<0.05)$. Age-sex specific mean values of skinfold thicknesses of TSF, SSF, SISF and PBF of girls were observed to be significantly higher than boys $(p<0.05)$. The age-sex specific mean values of BSF, TSF, SSF, SISF, $\sum 4$ SKF and PBF did not show any age-specific trend in children. Comparison with the NHANES-III data showed poor attainment of subcutaneous adiposity and nutritional status. Conclusion: Results of the present study showed the age-sex specific variations in subcutaneous adiposity pattern in children. The comparisons of skinfold thicknesses with references showed unsatisfactory nutritional status among children. These findings are important for future investigations in field, epidemiological and clinical settings.

Key words: Anthropometry, Body Composition, Nutritional Assessment, Skinfold thickness, Sexual Dimorphism, Subcutaneous Adiposity

\section{Introduction}

A nthropometric measures are still considered to be reliable, noninvasive, and inexpensive and widely used technique to assess physical growth and nutritional status. The measures mostly comprise of height, weight and skinfold thickness measurements ${ }^{1}$. Body mass index $\left(\mathrm{BMI}, \mathrm{kg} / \mathrm{m}^{2}\right)$ is also widely used as an index of body fatness
${ }^{1}$ Mrs. Sampriti Debnath, M.Sc., UGCSenior Research Fellow. Department of Anthropology, University of North Bengal, Dist: Darjeeling-734013, West Bengal, India, ${ }^{2}$ Dr. Nitish Mondal, Ph.D., Assistant Professor, Department of Anthropology, Assam University (Diphu Campus), Dist: Karbi Anglong-782462, Assam, India, ${ }^{3}$ Dr. Jaydip Sen Ph.D., Professor, Department of Anthropology, University of North Bengal, Dist: Darjeeling-734013, West Bengal, India

\author{
Address for correspondence \\ Dr. Jaydip Sen (Professor) \\ Department of Anthropology, \\ University of North Bengal, Raja Rammohunpur, \\ Darjeeling-734013, West Bengal, India. \\ Tel No; +91-9932268224 \\ E-mail:jaydipsen@rediffmail.com
}

Acknowledgements: The help and co-operation of the children, their parents and authorities of the primary schools of Phansidewa Block and the Department of Anthropology, North Bengal University are acknowledged.

Funding: Financial assistance in the form of University Grants Commission-Junior research Fellowship [Reference No: 674/(NET-JUNE 2014)] to the first author is also acknowledged. Conflict of Interest: None

Permission from IRB: Yes

\section{How to cite}

Debnath S, Mondal N, Sen J. Subcutaneous Adiposity and Nutritional Status Among Children of Eastern-India. J Nepal Paediatr Soc 2018;38(1):38-45.

doi: http://dx.doi.org/10.3126/jnps.v38i1.18750

This work is licensed under a Creative Commons Attribution 3.0 License. 
and is a measure of weight relative to height rather than of adiposity. It is used as a global proxy of nutritional status and highly correlated with different components of weight (e.g., lean mass or fat free mass, fat mass, skeletal muscle mass and bone mass), however, it is unable to provide differentiation between them ${ }^{2}$. The increase in BMI levels during puberty seems to be largely the result of increase in fat-free mass (e.g., muscle mass) rather than body fatness (e.g., adiposity) which further complicates the interpretation of physical growth among children and adolescents $s^{3,4,5,6,7}$. Variations in relative distribution of adipose tissue in the human body is an important area of research and it can be related with several preventable non-communicable diseases (e.g. cardiovascular diseases, metabolic disorders and gastrointestinal abnormalities, hyperlipidaemia, sleep apnoea, hepatic steatosis, polycystic ovary disease, and glucose intolerance $)^{2,6}$. The distribution of adipose tissue is also associated with physical growth and maturation $^{8,9,10,11}$. Epidemiologic evidence supports the theory that relation between excess adiposity (e.g., obesity) and relative risk of disease burden begins early in life 8,11 . Accumulation of higher adiposity levels tend to advance bone ages and early physical growth attainment and maturation in children ${ }^{12,13}$

Skinfold measurements of subcutaneous adiposity have a long history in human nutrition and body composition assessment related research ${ }^{9,14}$ and have been widely used to determine the population specific body composition and relative subcutaneous adiposity distribution ${ }^{3,15,16}$. Amount of subcutaneous body adiposity is very specific to adipose tissue and can be determined using non-invasive techniques (e.g., anthropometry) $)^{1,3,5}$. Therefore, skinfold thickness is an important, useful and valid anthropometric measure of regional and total body adiposity in clinical or epidemiological research settings ${ }^{1,11,15,16,17}$. Skinfold thickness has been used extensively for estimating the changes in subcutaneous adiposity and body composition, and observed to be very useful technique due to its easy-to-use and noninvasive nature in research studies $3,9,14,15,18,19$. Adipose tissue accumulation is mostly dependent on nutritional status, age-sex specific and ethnic variation, and skinfold thicknesses are widely used as a practical tool for assessment of nutritional status in field, epidemiological or clinical settings $s^{2,3,5,8,17}$. Several researchers have reported age-sex variations in subcutaneous adiposity pattern, nutritional status and body composition using skinfold thicknesses among children $3,9,17,19,20$. The objectives of the present study were to determine the age-sex specific subcutaneous adiposity and assessment of nutritional status using skinfold thickness among rural children of Eastern-India.

\section{Material and Methods}

The present cross-sectional investigation was carried out among 1262 school-going children (boys: 619; girls: 643) aged 5-12 years residing in rural areas of Phansidewa Block, Darjeeling district, West Bengal, India. This community block (Latitude $26^{\circ} 34^{\prime} 59^{\prime \prime} \mathrm{N}$, Longitude $88^{\circ} 22^{\prime} 00^{\prime \prime} \mathrm{E}$ ) is situated near the IndoBangladesh border region and $\sim 35-40 \mathrm{~km}$ from the subdivisional town of Siliguri and covers an area of 308.65 $\mathrm{km}^{2}$. The community block has availability of all the basic amenities, such as hospitals, schools, markets, post office and government offices ${ }^{3}$. The minimum number of participants required for the present investigation was estimated following the standard sample size estimation method ${ }^{21}$. In this method, the expected population proportion of $50 \%$, absolute precision of $3 \%$ ( $\leq 5 \%$; i.e., the lower margin of error) and confidence interval of $95 \%$ were taken into consideration. The minimum number of sample size estimated for the present investigation was 1068 individuals. Finally, 1262 children (619 boys; 643 girls) aged 5-12 years were selected to take part in the investigation. The socioeconomic data on age, sex, parents' occupation and nature of occupation, parents' education, monthly family income, family size, family types, house-conditions, electricity facility, and drinking water and toilet facilities were collected using a structured schedule. A modified version Kuppuswamy's socio-economic scale was used to evaluate the socio-economic status (SES) of the children $^{22}$. The determination of SES showed that all the children belonged to lower-middle SES. The data of the present investigation was collected during the period from September 2014 to November 2015.

Anthropometric measurements recorded: Anthropometric measurements were recorded using standard anthropometric procedures ${ }^{1}$. The skinfold measurements of biceps (BSF), triceps (TSF), subscapular (SSF) and supra-iliac (SISF) were measured using a Holtain skinfold calliper (London University Institute of Child Health, UK) on the left side of each child to the nearest to $0.2 \mathrm{~mm}$. For calculating intraobserver and inter-observer technical errors of the measurements (TEM) ${ }^{23}$, BSF, TSF, SSF and SISF were recorded from different data set of 50 children other than those selected for the investigation by SD and JS. Very high values of coefficient of reliability $(R>0.975)$ were obtained for BSF, TSF, SSF and SISF and these values were observed to be within the recommended cut-off of $0.95^{23}$. Hence, the measurements recorded by SD and JS were considered to be reliable and reproducible. All the measurements in course of the present investigation were recorded by SD. The sum of two skinfolds ( $\left.\sum 2 \mathrm{SKF}\right)$ 
and sum of four skinfolds ( $\sum 4 \mathrm{SKF}$ ) were calculated using the following standard equations:

$$
\begin{aligned}
& \sum 2 \mathrm{SKF}(\mathrm{mm})=\mathrm{TSF}+\mathrm{SSF} \\
& \sum 4 \mathrm{SKF}(\mathrm{mm})=\mathrm{BSF}+\mathrm{TSF}+\mathrm{SSF}+\mathrm{SISF}
\end{aligned}
$$

The body density (D) was calculated for the evaluation of peripheral adiposity or percent of body fat (PBF) using the standard equations of Deurenberg et al. ${ }^{24}$ :

$$
\begin{aligned}
& D_{\text {Boys }}=1.1133-0.0561\left(\log \sum 4 S K F\right)+1.7\left(\text { age }^{*} 10^{-3}\right) \\
& D_{\text {Girls }}=1.1187-0.0630\left(\log \sum 4 S K F\right)+1.9\left(\text { age }^{*} 10^{-3}\right)
\end{aligned}
$$

The assessment of peripheral adiposity or PBF of the children was calculated using the standard equation of Westrate and Deurenberg ${ }^{25}$ :

$$
\mathrm{PBF}=[562-4.2(\text { age }-2)] / D-[525-4.7(\text { age }-2)]
$$

The data were statistically analysed using the Statistical Package for Social Sciences (SPSS, Inc., Chicago, IL; version 17.0). Descriptive statistical analysis of the data obtained was depicted in terms of mean and standard deviation ( $\pm S D$ ). One-way analysis of variance (ANOVA) was performed to assess agespecific mean differences in anthropometric variables of the groups using Scheffe procedure. Independent sample t-test was done to assess sex-specific mean differences in anthropometric variables. The LMS model was utilized to convert the measurements for children of known age-sex to evaluate the centiles ${ }^{26,27}$. The LMS Chart Maker software program (The Institute of Child Health, London) was used to obtain the smooth centile curves. The method summarizes percentiles at each age based on the power of age-specific Box-Cox power transformations used to normalize data. The centile curves $\left(3^{\text {rd }}, 10^{\text {th }}, 25^{\text {th }}, 50^{\text {th }}, 75^{\text {th }}, 90^{\text {th }}\right.$ and $\left.97^{\text {th }}\right)$ were derived as reference data for further evaluation of body composition. A p-value of $<0.05$ was considered to be statistically significant.

\section{Results}

Age and sex-specific subject distribution, means and standard deviations of BSF, TSF, SSF, SISF, ¿2SKF and $\sum 4$ SKF among the boys and girls are depicted in Table 1. Age-specific mean skinfold value was observed to be slightly higher among girls than boys, especially in TSF and SSF in older age groups (e.g. 10-12 years). Age-specific mean BSF and SISF were observed to be higher in younger age groups (e.g., 5-8 years). The mean values of $\sum 4$ SKF were observed to be higher among boys than girls of younger age groups (e.g. 5-8 years) and higher among girls than boys in older age groups (9-12 years). The age-specific PBF ranged from $13.24 \%$ (in 11 years) to $15.29 \%$ (in 5 years) (in boys) and $14.91 \%$ (in 8 years) to $17.22 \%$ (in 10 years) (in girls). The age-specific mean differences were observed to be statistically significant using ANOVA for all the variables of boys and girls $(p<0.05)$ except in case of boys in TSF, SSF, $\sum 2$ SKF and $\sum 4$ SKF $(p>0.05)$. The results of the independent sample t-test showed statistically significant $(p<0.05)$ sex-specific differences in overall mean values of TSF (F-value $=48.81$, d.f.,1,1261), SSF (F-value $=73.58$, d.f.,1,1261), SISF (F-value= 32.15, d.f.,1,1261), PBF (F-value= 53.91, d.f.,1,1261), S2SKF (F-value $=65.46$, d.f.,1,1261) and $\sum 4$ SKF $(F-$ value $=28.06$, d.f.,1,1261 $)(p<0.05)$. Age-specific LMS percentile curves of BSF, TSF, SSF and SISF for girls showed an ascending trend which is absent in boys. Sexual dimorphism appeared to be in TSF, SSF, SISF, PBF, $\sum 2$ SKF and $\sum 4$ SKF measurements between sexes $(p<0.05)$. Age-sex specific percentile curves of BSF, TSF, SSF and SISF using LMS for assessment of nutritional status is depicted in Figure 1.

Assessment of nutritional status: The assessment of nutritional status was done by comparing the age and sex specific mean values of TSF, SSF and $\Sigma T S F+S S F$ using the reference values of NHANES-III reference ${ }^{28}$ (Figure 2). The comparison of the present investigation with reference population showed that the age-sex specific mean TSF values of the boys and girls were $<25^{\text {th }}$ percentile which were below normal mean values of TSF. The mean SSF values were found to be $<50^{\text {th }}$ percentile among boys and girls, respectively. The age-sex specific mean values of SISF of majority of boys and girls were $<50^{\text {th }}$ percentile of the reference. The mean values of sum of $\sum 2 \mathrm{SKF}$ of boys and girls were $<50^{\text {th }}$ percentile. Therefore, poor nutritional status of the children was observed with reference to the NHANES-III reference population ${ }^{28}$. Age-specific mean values were observed to be $<50^{\text {th }}$ percentile (e.g., TSF, SSF, SISF and $\sum 2$ SKF) in age groups of 5-7 years in both sexes, but the mean values were observed to be almost on $<25^{\text {th }}$ percentile values of reference in 10-11 years in TSF, SSF, SISF and $\sum 2$ SKF. Exceptions were observed in 12 years where TSF and SSF values of girls were in $<25^{\text {th }}$ percentile, TSF and SSF values on $25^{\text {th }}$ percentile, SISF values were on $25^{\text {th }}$ percentile (in boys) and on $5^{\text {th }}$ percentile (in girls) and $\sum 2 S K F$ values were on $25^{\text {th }}$ percentile for boys and in $<25^{\text {th }}$ percentile in girls (Figure 2). 


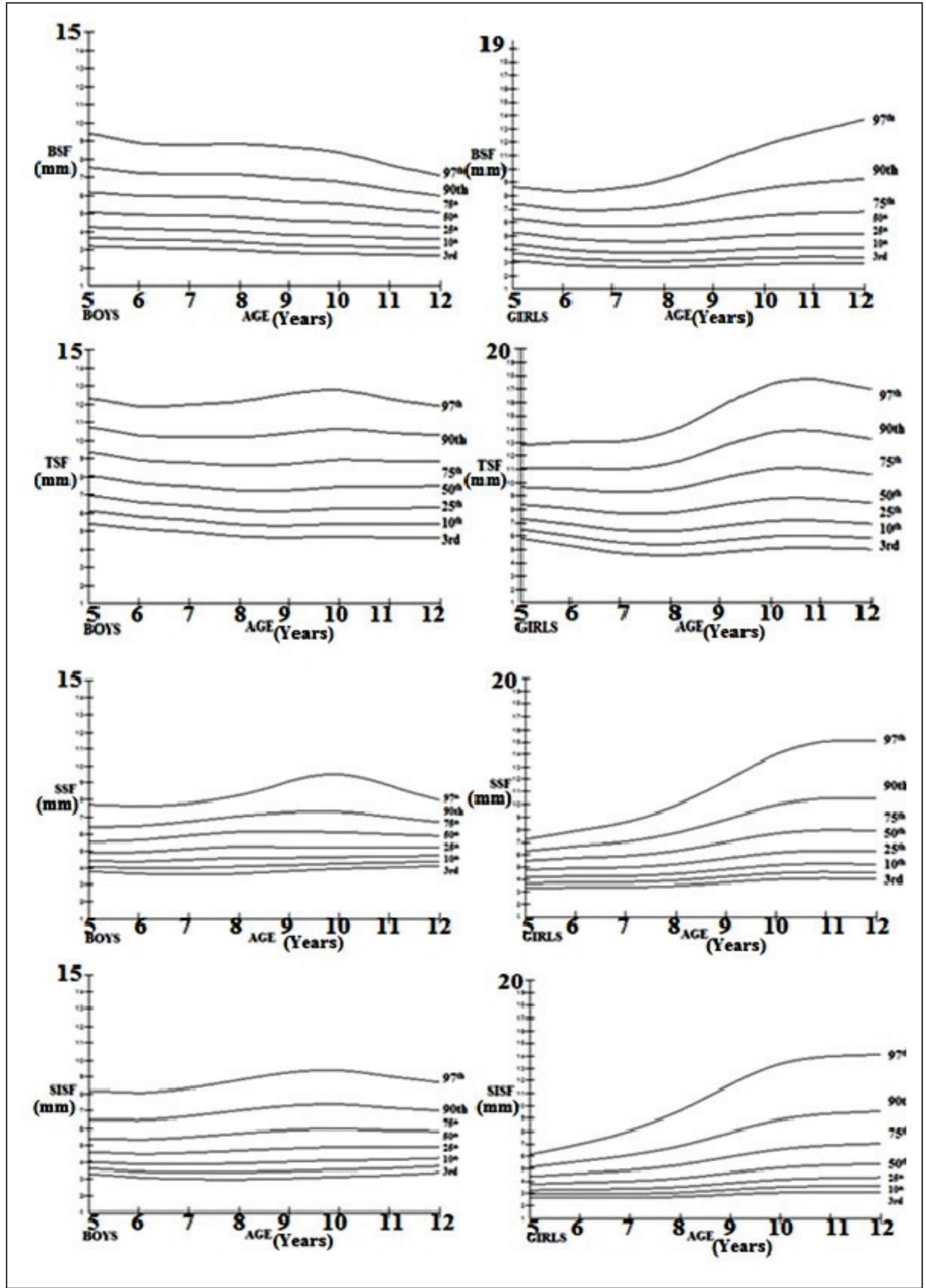

Fig. 1: Age-sex specific LMS graphs of BSF, TSF, SSF and SISF among the children 


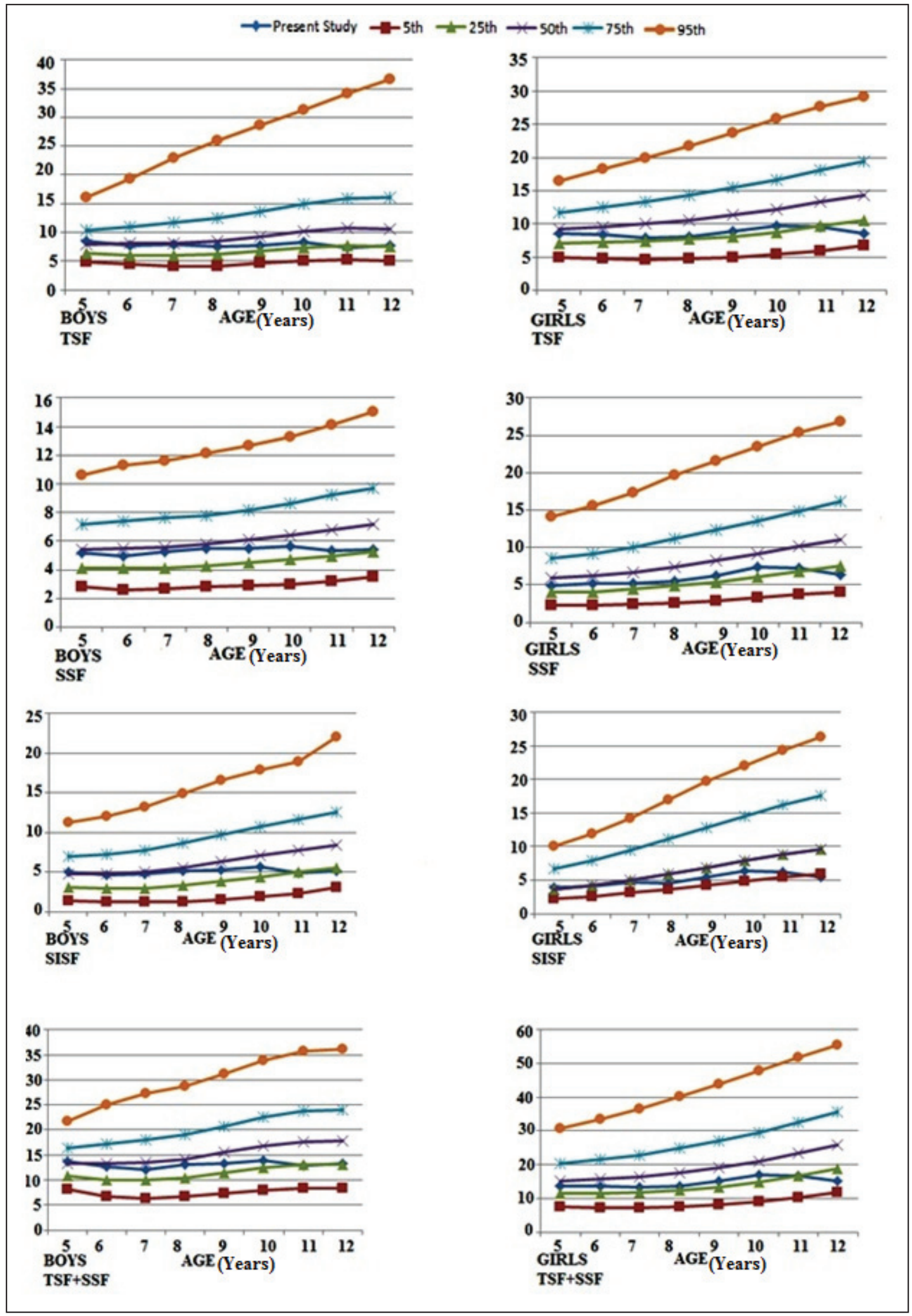

Fig. 2: Comparison of TSF, SSF and $\sum$ TSF+SSF with NHANES-III reference ${ }^{28}$ population among the children 
Table 1: Age-sex specific mean and standard deviation of anthropometric variables among the children

\begin{tabular}{|c|c|c|c|c|c|c|c|c|c|c|c|c|c|c|}
\hline \multirow{2}{*}{$\begin{array}{c}\text { Age } \\
\text { Group }\end{array}$} & \multicolumn{2}{|c|}{ BSF (mm) } & \multicolumn{2}{|c|}{ TSF (mm) } & \multicolumn{2}{|c|}{ SSF (mm) } & \multicolumn{2}{|c|}{ SISF (mm) } & \multicolumn{2}{|c|}{$\sum 2 S K F(\mathrm{~mm})$} & \multicolumn{2}{|c|}{$\sum 4 \mathrm{SKF}(\mathrm{mm})$} & \multicolumn{2}{|c|}{ PBF } \\
\hline & Boys & Girls & Boys & Girls & Boys & Girls & Boys & Girls & Boys & Girls & Boys & Girls & Boys & Girls \\
\hline 5 & 7.36 & 5.54 & 8.46 & 8.59 & 5.23 & 4.89 & 5.07 & 3.93 & 3.69 & 13.53 & 26.12 & 22.98 & 5.29 & 5.89 \\
\hline Years & 1.74 & 1.58 & 2.22 & 1.90 & 1.83 & 1.07 & 2.00 & .00 & \pm 3.76 & 2.69 & \pm 16 & & 10 & \pm 2.63 \\
\hline 6 & 5.03 & 4.88 & 7.67 & 8.47 & 5.00 & 5.21 & 4.69 & 07 & 12.67 & 13.68 & 22.39 & 22.63 & 13.98 & 15.41 \\
\hline years & \pm 1.21 & \pm 1.30 & \pm 1.51 & \pm 2.07 & \pm 0.95 & \pm 1.26 & \pm 1.19 & \pm 1.00 & \pm 2.13 & \pm 3.08 & \pm 3.90 & 50 & \pm 2.06 & \pm 2.61 \\
\hline 7 & .17 & 4.97 & 7.85 & 98 & 5.29 & 5.16 & 4.82 & 7 & 12.13 & 13.22 & 23.13 & 80 & 14.19 & 15.10 \\
\hline & \pm 1.41 & \pm 1.56 & \pm 1.75 & \pm 2.19 & & & & & \pm 2.40 & & \pm 4.45 & & & \pm 3.25 \\
\hline 8 & 5.20 & 4.85 & 7.53 & & & & & & & & & & & 14.91 \\
\hline years & \pm 1.46 & \pm 1.62 & \pm 2.00 & \pm 2.30 & \pm 1.40 & \pm 1.72 & \pm 1.66 & \pm 1.51 & \pm 3.07 & \pm 3.74 & \pm 5.39 & \pm 5.84 & \pm 2.68 & \pm 3.20 \\
\hline 9 & 4.98 & 5.48 & 7.73 & 8.88 & 5.52 & 6.29 & 5.26 & 5.41 & 13.25 & 15.21 & 23.48 & 26.06 & 13.85 & 16.17 \\
\hline years & \pm 2.30 & \pm 2.54 & \pm 2.89 & \pm 3.21 & \pm 1.90 & \pm 2.36 & \pm 2.10 & \pm 2.76 & \pm 4.32 & 31 & \pm 8.18 & 16 & \pm 3.18 & \pm 4.01 \\
\hline 10 & 5.09 & 5.54 & 8.27 & 9.75 & 5.65 & 7.38 & 5.66 & 6.34 & 13.92 & 17.13 & 24.67 & & 14.47 & 17.22 \\
\hline years & \pm 1.45 & \pm 2.30 & \pm 2.44 & \pm 3.59 & \pm 1.25 & \pm 3.83 & \pm 2.04 & \pm 3.95 & \pm 3.27 & \pm 7.10 & \pm 6.04 & \pm 11.48 & \pm 2.76 & \pm 4.40 \\
\hline 11 & 4.45 & 5.95 & 7.42 & 9.56 & 5.38 & 7.27 & 4.92 & 6.17 & 12.80 & 16.80 & 22.17 & 28.94 & 13.24 & 17.06 \\
\hline years & \pm 1.23 & \pm 2.77 & \pm 1.75 & \pm 3.52 & \pm 1.15 & \pm 3.24 & \pm 1.16 & \pm 2 & \pm 2 & \pm 6 & \pm 4.57 & 18 & \pm 2 & \pm 4.16 \\
\hline 12 & 4.44 & 5.82 & 7.78 & 8.55 & 5.43 & 6.41 & 5.19 & 5.53 & 13.21 & 15.03 & 22.85 & 31 & 13.57 & 15.91 \\
\hline ears & \pm 1.08 & \pm 2.97 & \pm 1.81 & \pm 2.13 & \pm 0.95 & \pm 2.08 & \pm 1.37 & \pm 2.15 & \pm 2.42 & \pm 3.80 & \pm 4.12 & 11 & \pm 2.00 & \pm 3.11 \\
\hline & 5.22 & 5.36 & 7.80 & 8.82 & 5.36 & 6.17 & 5.06 & 5.22 & 13.17 & 15.01 & 23.45 & 25.57 & 14.10 & 16.07 \\
\hline & \pm 4.52 & \pm 2.18 & \pm 2.12 & \pm 2.93 & \pm 1.38 & \pm 2.68 & \pm 1.67 & \pm 2.88 & \pm 3.12 & \pm 5.31 & \pm 7.36 & \pm 8.72 & \pm 2.76 & \pm 3.73 \\
\hline F-value & 2.36 & 2.90 & 1.83 & 4.88 & 1.73 & 12.49 & 2.39 & 9.12 & 1.19 & 8.29 & 1.92 & 9.66 & 2.81 & 5.08 \\
\hline$p$-value & 0.02 & 0.00 & 0.08 & 0.00 & 0.09 & 0.00 & 0.02 & 0.00 & 0.31 & 0.00 & 0.06 & 0.00 & 0.007 & 0.00 \\
\hline
\end{tabular}

*Age-specific mean differences, $\pm \mathrm{SD}=$ standard deviations

\section{Discussion}

Human adiposity in body composition assessment is a resource for the energy cost required for growth, reproduction, immune function, heritability and hormonal secretions of adipose tissue which play a key regulatory role in these functions ${ }^{2}$. Population/ ethnic variations in adiposity and nutritional status can be attributed to several associated factors (e.g. sex, ethnicity, diet, physical exercise patterns, socio-economic status, environment and burden of infectious disease) $)^{3,5,16,19,29,30,31,32,33,34}$. Age-specific body adiposity increase has significant influence on the variation of subcutaneous adipose tissue $e^{3,16,19,20,33,34,35}$. However, the pronounced sex-specific difference was absent in the subcutaneous adipose tissue before puberty. Studies conducted among children of US ${ }^{8,36}$, Netherlands $^{37}$ and Japan $^{38}$ showed insignificant sexdifference in abdominal and subcutaneous adipose tissue measured by skinfold thicknesses. Studies also showed that the attainment of puberty in girls tend to accumulate significantly higher adipose tissue than boys $^{3,16,19,29,35}$. Several studies have reported sexual dimorphism in subcutaneous adiposity patter among children $^{3,9,16,19,18,33,35}$. There were significant age-sex specific differences in subcutaneous adiposity pattern and PBF in children (Table 1). Several researchers have reported that the absolute skinfold thicknesses were higher in girls ${ }^{3,16,18,19,29,35}$ but the demarcation in relative skinfold thickness were observed during puberty due to the increase in peripheral adipose tissue deposition in girls ${ }^{5,9,29}$. Such variation in subcutaneous adiposity can be attributed to sex-specific and genetic variations, sex-steroid hormones and environmental factors and it also serves as a good indicator of nutritional status of children $^{5,3,19,32}$.

Sexual dimorphism in adiposity levels primarily attributed to the action of sex steroid hormones ${ }^{3,5}$. Estrogen increases the fat storage, resulting in higher adipose tissue storage in females than in males. Moreover, the skinfold thicknesses directly measure subcutaneous adiposity and contributes to $\mathrm{PBF}^{17,36}$. Therefore, lower levels of adipose tissue gives rise to low levels of PBF or body composition indicating the poor nutritional conditions in children (Figure 2). However, several studies have provided the usefulness and validity of skinfold thickness in assessing body composition and nutritional status ${ }^{10,16-20,29,35}$. Population/ ethnic differences are observed in the accumulation of adipose tissue among children ${ }^{8,10,33}$. The results of the present investigation showed significantly higher adiposity among girls than boys (Table 1). The higher age-groups reaching puberty showed higher differences and higher values of skinfold thicknesses than the lower age groups. Comparison with NHANES-III reference population ${ }^{28}$ showed very unsatisfactory nutritional status and also sex-specific differences in mean values 
were observed in children (Figure 2). Undernutrition is a major cause of concern in children and there is a scarcity of growth reference values for skinfold thickness (e.g. TSF, SSF, SISF and $\Sigma$ TSF+SSF) except the reference values published by Frisancho ${ }^{28}$ using NHANES-III data. This was why the results of the present investigation were compared to assess nutritional status and body composition. Several studies have reported that the children residing in rural areas were observed to be more vulnerable to unsatisfactory nutritional status than their urban counterparts where prevalence of overweight-obesity has become a cause of concern ${ }^{3,30,32}$. The lower adiposity levels among children could be the major indicator of undernutrition, which is actually being more frequent than overweight-obesity among Indian children $^{3,19,20,30,32}$. The results of the present investigation will be useful for nutritionist, paediatrician and policy makers in their endeavour to formulate nutrition sensitive developmental and/or intervention strategies related to nutritional status and subcutaneous adiposity (i.e., body composition). Further studies should be conducted to formulate new ethnic specific standards and to identify the population specific undernutrition and body composition using skinfold among vulnerable segments of population.

\section{Conclusion}

Results of the present investigation showed the agesex specific variations in subcutaneous adiposity pattern and subcutaneous adiposity was significantly greater among girls than boys. The comparisons of skinfold thicknesses with references showed unsatisfactory nutritional status among children. Hence, appropriate nutrition sensitive intervention programmes are necessary to ameliorate the nutritional situation. These findings are also important for future investigations in field, epidemiological and clinical settings.

\section{References}

1. Hall JG, Allanson JE, Gripp KW, Slavotinek AM. Handbook of Physical Measurements. New York: Oxford University Press 2007.

2. Wells JCK. The evolutionary biology of human body fatness: thrift and control.-Cambridge: Cambridge University Press 2010.

3. Sen J, Mondal N. Fat mass and fat free mass as indicators of body composition among Bengalee Muslim children. Ann Hum Biol 2013;40:286-93. DOI: 10.3109/03014460.2013.764014.

4. Adair LS, Fall $\mathrm{CH}$, Osmond C, Stein AD, Martorell R, Ramirez-Zea M, Sachdev HS, Dahly DL, Bas I, Norris SA, Micklesfield L. Associations of linear growth and relative weight gain during early life with adult health and human capital in countries of low and middle income: findings from five birth cohort studies. Lancet 2013;382:525-34.DOI: 10.1016/ S0140-6736(13)60103-8.

5. Wells JC. Sexual dimorphism of body composition. Best Pract Res Clin Endocrinol Metabol 2007;21:41530. DOI: https://doi.org/10.1016/j.beem.2007.04.007

6. Freedman DS, Sherry B. The validity of BMI as an indicator of body fatness and risk among children. Pediatrics 2009;124:S23-S34. DOI: 10.1542/ peds.2008-3586E.

7. Jeddi, M, Dabbaghmanesh MH, Omrani GR, Ayatollahi SMT, Bagheri, Z, Bakhshayeshkaram M. Relative importance of lean and fat mass on bone mineral density in Iranian children and adolescents. Int J Endocrinol Metabol 2015;13:e25542. DOI: 10.5812/ ijem.25542v2.

8. Goran MI, Kaskoun MC, Shuman WP. Intraabdominal adipose tissue in young children. Int $J$

Obes 1995;19:279-83. DOI: https://doi.org/10.1038/ sj.ijo.0800624.

9. Malina RM., Koziel S, Bielicki T. Variation in subcutaneous adipose tissue distribution associated with age, sex, and maturation. Am $J$ Hum Biol 1999;11:189-200. DOI: https://doi. org/10.1002/(SICI)1520-6300(1999)11:2<189::AIDAJHB7>3.0.CO;2-\#

10. Staiano AE, Broyles ST, Gupta AK, Katzmarzyk PT. Ethnic and sex differences in visceral, subcutaneous, and total body fat in children and adolescents. Obesity 2013;21:1251-55. DOI: 10.1002/oby.20210.

11. Martinez EE, Smallwood CD, Quinn NL, Ariagno K, Bechard LJ, Duggan CP, Mehta NM. Body Composition in Children with Chronic Illness: Accuracy of Bedside Assessment Techniques. J Pediatr 2017;190:56-62. DOI: 10.1016/j.jpeds.2017.07.045.

12. Wang Y. Is obesity associated with early sexual maturation? A comparison of the association in American boys versus girls. Pediatrics 2002;110:90310. DOI: 10.1542/peds.110.5.903.

13. Dai $Y L, F u ~ J F$, Liang L, Gong CX, Xiong F, Luo FH, Liu GL, Chen SK. Association between obesity and sexual maturation in Chinese children: a multicenter study. Int J Obesity 2014;38:1312-16. DOI: 10.1038/ ijo.2014.116.

14. Ramírez-Vélez R, López-Cifuentes MF, CorreaBautista JE, González-Ruíz K, González-Jiménez E, Córdoba-Rodríguez DP, Vivas A, Triana-Reina HR, Schmidt-RioValle J. Triceps and subscapular skinfold thickness percentiles and cut-offs for overweight and obesity in a population-based sample of schoolchildren and adolescents in Bogota, Colombia. Nutrients 2016;8:595. DOI:10.3390/nu8100595. 
15. Bedogni G, Lughetti L, Ferrari M, Malavolti M, Poli M, Bernasconi S, Battistini N. Sensitivity and specificity of body mass index and skinfold thicknesses in detecting excess adiposity in children aged 8-12 years. Ann Hum Biol 2003;30:132-39. DOI: https://doi.org/10.1080/030 1446021000033409 .

16. Satake E, Nakagawa $Y$, Kubota A, Saegusa H, Sano S-iOhzeki T. Age and sex differences in fat distribution in non-obese Japanese children. J Pediatric Endocrinol Metab 2010;23:873-78. DOI: https://doi.org/10.1515/ jpem.2010.141.

17. Yuca SA, Cesur Y, Yilmaz C, Mazicioglu M, Kurtoglu S. Assessment of nutritional status: Tricepsand subscapular skinfold thickness in Turkish children and adolescent. Pak J Med Sci 2011;27:115-19.

18. Webster-Gandy J, Warren J, Henry CJ. Sexual dimorphism in fat patterning in a sample of 5 to 7 -yearold children in Oxford. Int J Food Sci Nutr 2003;54:46771. DOI: https://doi.org/10.1080/09637480310001322 323.

19. Debnath S, Mondal N, Sen J. 2017. Use of upper arm anthropometry, upper arm muscle area-byheight (UAMAH) and mid upper-arm-circumference (MUAC)-for-height as indicators of body composition and nutritional status among children. Anthropol Rev 80:85-102. DOI: https://doi.org/10.1515/anre-20170004.

20. Chowdhury SD, Ghosh T. Prediction of nutritional status from skinfold thickness in undernourished Santal children of Purulia district, India. Anthropol Anz 2013;70:165-78. DOI: 10.1127/0003-5548/2013/0288.

21. Lwanga SK, Lemeshow S. Sample size determination in health studies: A Practical Manual. Geneva: World Health Organization 1991.

22. Kumar N, Shekhar C, Kumar P, Kundu AS. 2007. Kuppuswamy's socioeconomic status scale - Updating for 2007. Ind J Pediatr 74:1131-32.

23. Ulijaszek SJ, Kerr DA. Anthropometric measurement error and the assessment of nutritional status. Br J Nutr 1999;82:165-77. DOI: 10.1017/S0007114599001348.

24. Deurenberg P, Pieters JJL, Hautvast JGAJ. The assessment of the body fat percentage by skinfold thickness measurements in childhood and young adolescence. $\mathrm{Br} J$ Nutr 1990;63:293-303. DOI: 10.1079/BJN19900116.

25. Westrate JA, Deurenberg P. Body composition in children: proposal for a method for calculating body fat percentage from total body density or skinfold-thickness measurements. Am J Clin Nutr 1989;50:1104-15. DOI:10.1093/ajcn/50.5.1104.

26. Cole TJ, Green PJ. Smoothing reference centile curves: the LMS method and penalized likelihood. Stat Med 1992;11:1305-319. DOI:10.1002/sim.4780111005.
27. Cole TJ, Freeman JV, Preece MA. British 1990 growth reference centiles for weight, height, body mass index and head circumference fitted by maximum penalized likelihood. Stat Med 1998;17:407-29. DOI: 10.1002/(SICI)1097-0258(19980228)17:4<407::AIDSIM742>3.0.CO;2-L.

28. Frisancho AR. Anthropometric standards for the assessment of growth and nutritional status. University of Michigan Press 1990.

29. Taylor RW, Grant AM, Williams SM, Goulding A. Sex Differences in Regional Body Fat Distribution from Pre to Post puberty. Obesity 2010;18:1410-16. DOI: 10.1038/oby.2009.399

30. Sen J, Mondal N, Dey S. Assessment of the nutritional status of children aged 5-12 years using upper arm composition. Ann Hum Biol 2011;38:752-59. DOI: 10.3109/03014460.2011.610358.

31. Thibault R, Genton L, Pichard C. Body composition: why, when and for who? Clin Nutr 2012;3:435-47. DOI: 10.1016/j.clnu.2011.12.011.

32. Singh J, MondalN. Use of upper-arm anthropometry as measure of body composition and nutritional assessment in children and adolescents (6-20 Years) of Assam, Northeast India. Ethiop J Health Sci 2014;24:243-52. DOI: http://dx.doi.org/10.4314/ejhs. v24i3.8.

33. Lee S, Kuk JL, Hannon TS, Arslanian SA. Race and gender differences in the relationships between anthropometrics and abdominal fat in youth. Obesity 2008;16:1066-1071. DOI: 10.1038/oby.2008.13.

34. Marini E, Cabras S, Rebato E, Buffa R, Salces I, Borgognini-Tarli S. Sex differences inskinfold variability across human populations and during the life cycle. Ann Hum Biol 2007;34:377-92. DOI: https://doi. org/10.1080/03014460701367942.

35. Debnath S, Mondal N, Sen J. Percent of body fat, fat-mass, fat-free mass and assessment of body composition among rural school-going children of Eastern-India. Anthropol Rev 2018;81:158-73. DOI: https://doi.org/10.2478/anre-2018-0011.

36. Huang TTK, Johnson MS, Figueroa-Colon R, Dwyer JH, Goran MI. Growth of visceral fat, subcutaneous abdominal fat, and total body fat in children. Obesity Res 2001;9:283-89. DOI: https://doi.org/10.1038/ oby.2001.35.

37. Liem ET, Rolfe EDL, L'Abe'e C, Sauer PJJ, Ong KK, Stolk RP. Measuring abdominal adiposity in 6 to 7-year-old children. Eur J Clin Nutr 2009;63:835-41. DOI: 10.1038/ejcn.2008.57.

38. Asayama K, Hayashibe H, Endo A, Okada T, Hara M, Masuda H Sugihara S. Threshold values of visceral fat and waist girth in Japanese obese children. Pediatrics Int 2005;47:498-504. DOI: https://doi.org/10.1111/ j.1442-200x.2005.02117.x. 